\title{
Factores determinantes del desarrollo humano: un estudio de caso de la región San Martín - Perú
}

\section{Determinants of human development: a case study of the San Martín region - Peru}

Abraham Josué Horna-Rubio

Universidad César Vallejo, Lima, Perú

abrahamhorna@gmail.com

(D) https://orcid.org/0000-0002-7846-3377

Rita Haydeé Salazar-Tuanama

Universidad Norbert Wiener, Lima, Perú

rita.salazar@uwiener.edu.pe

(iD https://orcid.org/0000-0003-2746-9231

Kriss Melody Calla-Vásquez

Universidad San Ignacio de Loyola, Lima, Perú

kriss.calla@epg.usil.com

(D) https://orcid.org/0000-0003-4976-2332

Julia Lizet Torres-Rivera

Universidad Autónoma del Perú, Lima, Perú

julia.torres@autonoma.pe

(iD https://orcid.org/0000-0003-2848-4978

Recepción: 20/07/2021 | Aceptación: 15/10/2021 | Publicación: 30/10/2021

Cómo citar (APA, séptima edición):

Horna-Rubio, A. J., Salazar-Tuanama, R. H., Calla-Vásquez, K. M., y Torres-Rivera, J. L. (2021). Factores determinantes del desarrollo humano: un estudio de caso de la región San Martín - Perú. INNOVA Research Journal, 6(3.1), 167-192. https://doi.org/10.33890/innova.v6.n3.1.2021.1928

\section{Resumen}

El objetivo general de la presente investigación fue descubrir cuáles son los factores determinantes del desarrollo humano según la percepción de los agentes participantes en la Región San Martín. El tipo de investigación de la presente investigación es básica, de enfoque cualitativo, debido a que tiene por propósito comprender la realidad de los hechos y la interrelación de los factores 
intervinientes en el proceso de desarrollo de la Región San Martín. El diseño de la investigación fue estudio de caso, en la que se consideró la experiencia exitosa de la región San Martín. El instrumento para la recolección de datos fue la entrevista y análisis documental. Para la entrevista se utilizó como instrumento una guía de entrevista semi estructurada. El software utilizado para el análisis fue Atlas.ti versión 8.0; con este software se profundizó en los significados, fundamentándose en la codificación a partir de las dimensiones que han sido proyectadas para el análisis cualitativo a partir del guion de entrevistas, las mismas que se incluyen a continuación: Desarrollo Social (DS), Desarrollo Económico (DE), Desarrollo del Medio Ambiente (DMA), y Desarrollo Político Institucional (DPI) en la región de San Martín desde el año 2000 al 2020. En conclusión, se descubrió los factores determinantes del desarrollo humano según la percepción de los agentes participantes en la Región San Martín. Esta investigación encontró que los principales factores de Desarrollo Humano en la Región San Martín fue la "Migración", la "Cooperación Internacional", el "Turismo" y la "Capacidad de su gente".

Palabras claves: desarrollo humano; factores; agentes participantes; multidimensional.

\begin{abstract}
The general objective of this research was to discover which are the determining factors of human development according to the perception of the participating agents in the San Martín Region. The type of investigation of this investigation is basic, of a qualitative approach, because its purpose is to understand the reality of the facts and the interrelation of the factors involved in the development process of the San Martín Region. The research design was a case study, in which the successful experience of the San Martín region was considered. The instrument for data collection was the interview and documentary analysis. For the interview, a semi-structured interview guide was used as an instrument. The software used for the analysis was Atlas.ti version 8.0; With this software the meanings were deepened, based on the coding from the dimensions that have been projected for the qualitative analysis from the interview script, the same ones that are included below: Social Development (SD), Economic Development (DE), Environmental Development (DMA), and Institutional Political Development (DPI) in the San Martín region from 2000 to 2020. In conclusion, the determining factors of human development were discovered according to the perception of the participating agents in the San Martín Region. This research found that the main Human Development factors in the San Martín Region were "Migration", "International Cooperation", "Tourism" and the "Capacity of its people".
\end{abstract}

Keywords: human development; factors; participating agents; multidimensional.

\title{
Introducción
}

El desarrollo es un proceso ascendente que tiene por finalidad que los seres humanos sean felices, mejorando su nivel de vida y bienestar, disfrutando de libertad y capacidades para tomar decisiones y elegir cómo satisfacer sus necesidades. Desde el enfoque económico son factores determinantes del desarrollo, el crecimiento de la producción nacional, el aumento del ingreso per cápita, la industrialización, el avance tecnológico y la modernización de la sociedad. Sin embargo, en el paradigma de las libertades también depende de otros determinantes, como los planes sociales y económicos (servicios educativos y sanitarios), el ejercicio de los derechos civiles y políticos, (libertad para participar en debates y elecciones públicas), y el cuidado del medio ambiente para la sostenibilidad. (Sen, 2000a, 2000b). 
El Perú y los 32 millones de habitantes, en promedio, que conforman las diferentes regiones del país enfrentan grandes retos para lograr una mayor calidad de vida y bienestar; los desafíos son diversos, considerando las dimensiones: ambiental, social, económico, cultural e institucional. Para lograr tal propósito se necesita ir a la acción y tomar decisiones entre la sociedad y el Estado para producir cambios de actitud que mejoren sustancialmente al país. Los desafíos incluyen promover el diseño e implementación de políticas públicas ambientales, económicas, sociales e institucionales para que estén al servicio de las personas en sus territorios. (Centro de Planificación Nacional del Perú - CEPLAN, 2018).

A nivel nacional, la región San Martín ha tenido una gestión que ha sido catalogada de exitosa. Mucho se preguntan ¿Qué ocurrió en esta región para que su desarrollo económico, social, cultural e institucional haya sido diferente? ¿Por qué distintos analistas y medios hablan frecuentemente del "milagro" de San Martín? Algunos indicadores responden a tales interrogantes. Entre los años 2006 y 2011, el ingreso de los trabajadores se incrementó en 115\% en relación al $46 \%$ nacional y el aumento del empleo adecuado fue de $185 \%$ frente al promedio nacional de $82 \%$, en el mismo período. Los niveles de pobreza extrema se redujeron a razón de $3,3 \%$ al año y las de pobreza total lo hicieron al $8 \%$ anual; ambas tasas duplicaron la reducción que se registró a nivel nacional. El sector más importante de la región, la agricultura, tuvo un crecimiento anual de 6,5\%, alcanzando el nivel más alto del país. La producción de su producto bandera que constituye un importante eje económico, el cacao, se incrementó en $252 \%$ y duplicó su participación en la producción nacional. Es importante resaltar que dichos resultados se alcanzaron, pese a que San Martín ocupa el puesto 20 en relación al presupuesto público por habitante y cuenta con el $31 \%$ de menores recursos per cápita que el promedio del Perú (Ballón, 2015).

Por lo anterior mencionado, el problema a investigar son los factores determinantes del desarrollo humano como base del crecimiento de la región San Martín. Por ello, se precisa como objetivo general describir cuáles son los factores determinantes del desarrollo humano según la percepción de los agentes participantes en la región San Martín. Asimismo, como primer objetivo específico busca interpretar los factores determinantes del desarrollo social según la percepción de los agentes participantes en la región San Martín en 4 factores que conforman el eje social. El segundo objetivo específico es analizar los factores determinantes del desarrollo económico según la percepción de los agentes participantes en la región San Martín, en factores que conforman el eje económico. El tercer objetivo específico es comprender los factores determinantes del desarrollo del medio ambiente según la percepción de los agentes participantes en la región San Martín en 3 factores que conforman el eje medioambiental. Por último, el cuarto objetivo específico es interpretar los factores determinantes del Desarrollo Político Institucional, según la percepción de los agentes participantes en la Región San Martín en 3 dimensiones que conforman el eje político-institucional.

\section{Marco Teórico}

Checa-Olivas et al. (2021), en el artículo El impacto de la calidad del empleo y la calidad de la vivienda en el desarrollo humano en la unión europea, el objetivo fue aportar nueva información sobre cómo y a través de qué factores la calidad del empleo y la calidad de la vivienda se pueden mejorar desde un enfoque de desarrollo humano para que las personas puedan vivir la vida que desean. Utilizando el enfoque de las capacidades humanas como marco teórico de 
referencia, el artículo analiza el efecto del empleo a tiempo parcial involuntario y el hacinamiento en la vivienda con el Índice de Desarrollo Humano (IDH). El análisis empírico se basa en la técnica de datos de panel, que se aplica a los datos de la Oficina Europea de Estadística (Eurostat) y el Programa de las Naciones Unidas para el Desarrollo (PNUD) para los 28 países miembros de la Unión Europea. Los resultados arrojan nueva evidencia sobre cómo el trabajo a tiempo parcial involuntario y el hacinamiento en la vivienda limitan o impiden que las personas vivan la vida que desean, al menos en las dimensiones medidas por el IDH.

Libanio (2021) investigador de Agencia Nacional de Agua y Saneamiento de Brasil, Brasilia / DF, Brasil, publicó el artículo Servicios de WASH y desarrollo humano: un nexo tangible para alcanzar los ODS relacionados con el agua. Este documento examina las estadísticas mundiales sobre la disponibilidad de agua, la demanda de agua, el acceso a los servicios de agua, saneamiento e higiene (WASH) y el desarrollo humano en 2015, un año histórico para la transición de los Objetivos de Desarrollo del Milenio (ODM) de las Naciones Unidas a los nuevos Objetivos de Desarrollo Sostenible. Objetivos de desarrollo (ODS). Los resultados de las pruebas estadísticas no paramétricas señalan que, en la mayoría de los países, la dotación de agua, o la disponibilidad potencial de agua, no ha sido un factor determinante para la prosperidad económica y el desarrollo humano. Sin embargo, es posible delinear un fuerte nexo entre el agua y el desarrollo humano desde la perspectiva de las demandas de agua, particularmente cuando se consideran los usos primarios del agua para beber y saneamiento.

De otro lado, Zambrano et al., (2019) en La Igualdad de Género y el Desarrollo Humano. Especial Referencia a la República del Ecuador, manifiesta que el desarrollo humano, es un proceso que se vincula al mejoramiento de las condiciones de vida del personal, al acceder a bienes y servicios que les permiten satisfacer sus necesidades básicas. Desde esta mirada el desarrollo humano se relaciona con las alternativas que la sociedad brinda a las personas para que logren su desarrollo con dignidad. Concluye que, aún persiste desigualdad de género, por lo que es una problemática no resuelta.

Por su parte, Tapia (2020), en La determinación del factor espacial en el desarrollo humano: un análisis para el caso peruano, concluye que las oportunidades que tienen las personas para lograr resultados personales y sociales, dependen en forma significativa de la ubicación geográfica en la que se encuentren. Factores geográficos como la altitud, geografía y densidad poblacional, al igual que otros factores económicos, sociales e institucionales determinan el nivel de desarrollo humano en las diferentes regiones del Perú, y que la presencia del Estado, lejos de reducir las brechas de desigualdad, las termina fomentando.

Hurtado (2019), en Crecimiento económico, pobreza y desarrollo humano en el Perú, analiza la relación de las variables: crecimiento económico, pobreza, extrema pobreza y el nivel del desarrollo humano en el Perú, durante los años 1990 - 2018. Aplicando los métodos inductivo y deductivo se logró determinar que con un crecimiento del Producto Bruto Interno (PBI) de $4,90 \%$, se redujo la pobreza a $33,50 \%$ y extrema pobreza en $21.4 \%$, lo que permitió mejorar el Índice del Desarrollo Humano (IDH) pasando de 0.61 a 0.75 . Se concluye: para reducir los niveles de pobreza, extrema pobreza, se debe dinamizar y promover el crecimiento económico, incrementando el IDH. 


\section{Metodología}

El tipo de investigación del presente trabajo es básica, debido a que tuvo por propósito comprender e interpretar la realidad de los hechos y la interrelación de los factores intervinientes en el proceso de desarrollo de la región San Martín. De acuerdo a lo que indica el (Reglamento Del Sistema Nacional de Ciencia y Tecnología e Innovación Tecnológica - SINACYT, 2018) "la investigación básica está dirigida al conocimiento más completo mediante la comprensión de los aspectos fundamentales de los fenómenos, de los hechos observables o de las relaciones que establecen los entes”. Así como está dirigida a crear conocimiento.

La investigación es de enfoque cualitativo, dado que tiene por propósito descubrir y describir los factores que inciden en el desarrollo humano desde la percepción de los agentes participantes en el proceso de planificación y gestión del desarrollo. Se considera que "la investigación cualitativa se enfoca en comprender y profundizar los fenómenos, explorándolos desde la perspectiva de los participantes en un ambiente natural y en relación (Hernández-Sampieri et al., 2010).

El diseño de la investigación es el estudio de caso, en la que se consideró la experiencia exitosa de la región San Martín, los agentes participantes han sido 12, de los cuales el 25\% son migrantes, y el $75 \%$ son oriundos de la región. Estas personas han sido actores protagónicos en el proceso de desarrollo en la región, han experimentado, vivido y han aportado con ideas, propuestas y trabajo para que tal proceso alcance los logros que los ciudadanos sanmartinenses han deseado y desean alcanzar.

"El método de estudio de caso es una herramienta valiosa de investigación, y su mayor fortaleza radica en que a través del mismo se mide y registra la conducta de las personas involucradas en el fenómeno estudiado", según Monje (2010), citado en (Jimenez y Comet, 2016).

\section{Resultados}

El presente reporte busca describir los resultados obtenidos a través del análisis de la investigación cualitativa respecto a los factores determinantes del Desarrollo Humano. El software utilizado para el análisis fue Atlas. Ti versión 8.0; con este software se profundizó en los significados, fundamentándose en la codificación a partir de las dimensiones que han sido proyectadas para el análisis cualitativo a partir del guion de entrevistas, las mismas que se incluyen a continuación: Desarrollo Social (DS), Desarrollo Económico (DE), Desarrollo del Medio Ambiente (DMA), y Desarrollo Político Institucional (DPI) en la región de San Martín desde el año 2000 al 2020.

Sin embargo, como en toda investigación cualitativa de rigor, se han encontrado elementos que integran una parte importante de la comprensión del fenómeno del Desarrollo Humano, estos elementos son la "Migración" como parte del DS, el "Cooperativismo o Asociacionismo" como parte del DPI, y el "Desarrollo Cultural" que en este informe se ha incluido como parte del DS, considerándose "Desarrollo Socio-Cultura". A continuación, se hará la presentación de los resultados a través de las tablas descriptivas, y los gráficos de relación de hipervínculo que avala la teoría, juntamente con las tablas de co-ocurrencia de códigos que encuentran relación mediante 
el coeficiente "C", el mismo que ayudará para tener una interpretación más precisa de los fenómenos.

\section{Desarrollo General luego de los 90's}

\section{Tabla 1}

Desarrollo general luego de los años 90's en la región San Martín

\begin{tabular}{llll} 
Desarrollo general & & & \\
\hline Niveles & $\boldsymbol{n}$ & $\mathbf{\%}$ & \% acum. \\
\hline Se alcanzó un nivel importante de desarrollo & 5 & 41,67 & 41,67 \\
Se alcanzó un nivel medio de desarrollo & 5 & 41,67 & 83,33 \\
No es un tema relevante a tratar & 2 & 16,67 & 58,33 \\
Total & 12 & 100.00 & \\
\hline
\end{tabular}

En la Tabla 1 puede observarse en relación al desarrollo general que 41,67\% de los participantes considera que se alcanzó un nivel importante de desarrollo después de los 90's ya que empezó a cambiar la economía con una mayor variedad de productos que ofrecer en el mercado como son el café, arroz, cacao y otros que se consideran "productos bandera o estrella" para la región de San Martín, que luego de los 90's fueron el reemplazo directo de la coca que se sembraba en San Martín en la época del terrorismo, lo que fue posible también gracias a la carretera marginal que impulsó el comercio y el turismo. Sin embargo, aunque el avance ha sido considerable el otro $41,67 \%$ de participantes considera este avance como medio porque faltó expandir el desarrollo a las zonas más alejadas de los centros de San Martín (Tarapoto, Moyobamba), y en otros casos aún hay muchas cosas por mejorar en relación a los servicios básicos, deforestación, educación y salud. Por último, el 16,67\% de los participantes no hizo referencia al asunto, por lo que se debe entender como no relevante en el contexto actual.

\section{Factores que impulsaron el Desarrollo Humano}

\section{Tabla 2}

Factores que han determinado cambios en la región San Martín

\begin{tabular}{llll}
\hline Factores determinantes de cambios & & & \\
\hline Niveles & $\boldsymbol{n}$ & $\mathbf{\%}$ & \% acum. \\
\hline Cooperación Internacional & 4 & 16,67 & 16,67 \\
Capacidad de su gente & 6 & 25,00 & 41,67 \\
Visión de futuro de sus autoridades & 3 & 12,50 & 54,17 \\
Pacificación & 2 & 8,33 & 62,50 \\
Migración & 1 & 4,17 & 66,67 \\
Condiciones locales de tributaciones & 1 & 4,17 & 70,83 \\
Inversiones & 1 & 4,17 & 75,00 \\
Desarrollo industrial & 1 & 4,17 & 79,17 \\
Turismo & 1 & 4,17 & 83,33 \\
Carretera marginal & 1 & 4,17 & 87,50
\end{tabular}

Esta obra se comparte bajo la licencia Creative Common Atribución-No Comercial 4.0 International (CC BY-NC 4.0) Revista de la Universidad Internacional del Ecuador. URL: https://www.uide.edu.ec/ 


\begin{tabular}{llll}
\hline Factores determinantes de cambios & & & \\
\hline Niveles & $\boldsymbol{n}$ & $\boldsymbol{\%}$ & \% acum. \\
\hline Mesas técnicas & 1 & 4,17 & 81,67 \\
Organización & 1 & 4,17 & 95,83 \\
Descentralización & 1 & 4,17 & 100,00 \\
Total & 24 & 100,00 & \\
\hline
\end{tabular}

En la Tabla 2 puede observarse en relación a los factores que han determinado cambios en la región San Martín que 16,67\% veces los participantes hicieron referencia a que la "Cooperación Internacional" fue lo que más ayudó a la región de San Martín como un factor de cambio en relación a salir del narcotráfico y terrorismo, e impulsó el comercio. Asimismo 25,00\% veces los participantes hicieron referencia a que la "Capacidad de su Gente" fue lo que impulsó el cambio en la región de San Martín, ya sea porque son gente trabajadora y principalmente por su disposición a trabajar en equipo. Así también 12,50\% veces los participantes hicieron referencia a que la "Visión de futuro de sus Autoridades" fue un impulso importante para sacar adelante a la región de San Martín, y en especial se indica al gobierno de "César Villanueva" como un gestor de cambio. Un 8,33\% de las veces los participantes hicieron referencia a la "Pacificación" como un elemento importante de desarrollo humano para la región de San Martin, que se logró después de los 90's a causa de la erradicación del narcotráfico y el terrorismo. Por último 4,17\% veces los participantes hicieron referencia a la "Migración", "Condiciones locales de tributaciones", "Inversiones", "Desarrollo Industrial", "Turismo", "Carretera Marginal”, "Mesas Técnicas", "Organización”, y “Descentralización” como los factores de cambio de la Región de San Martín.

\section{Figura 1}

Factores que impulsaron el Desarrollo Humano en la región de San Martín

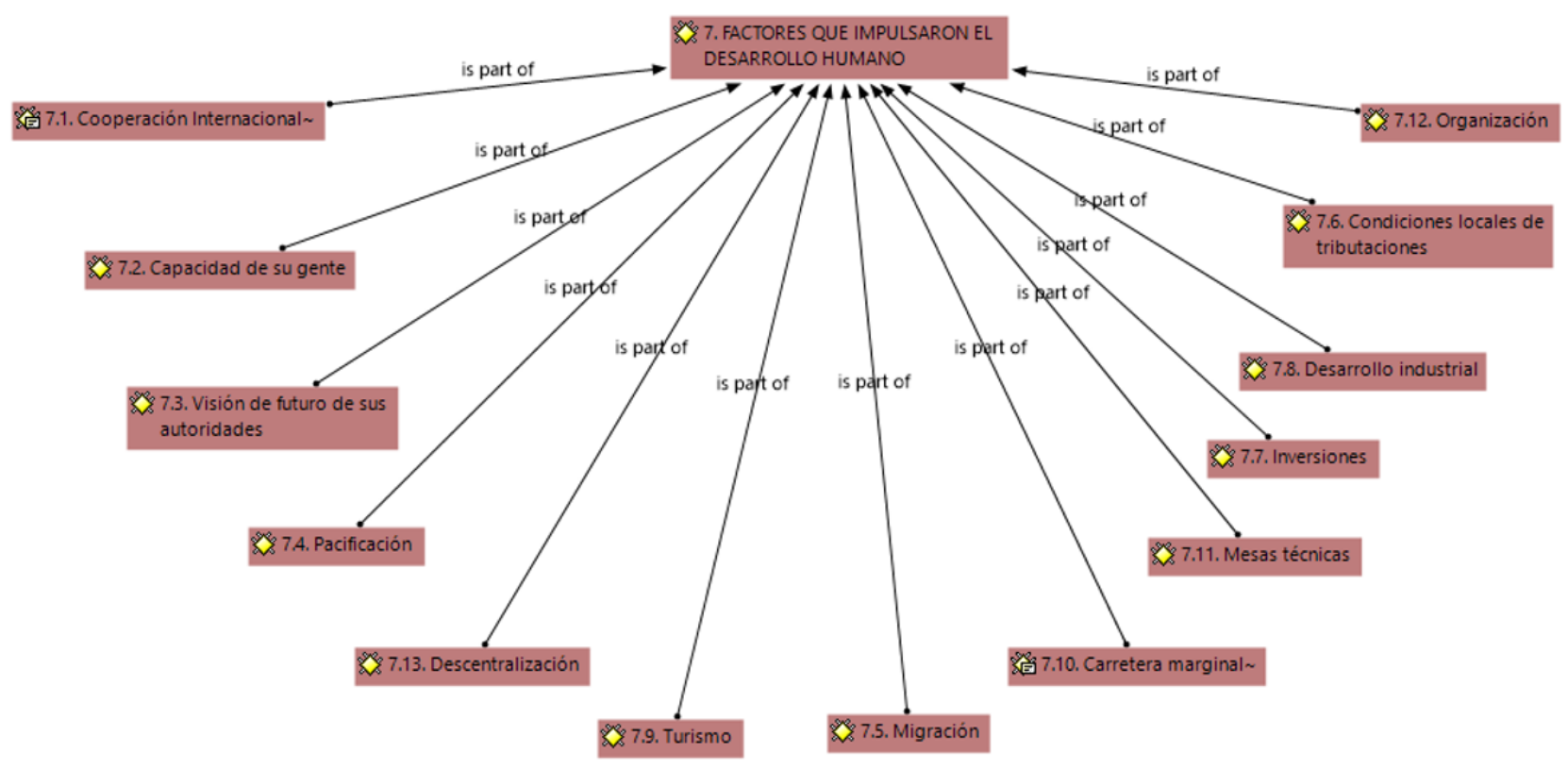

Esta obra se comparte bajo la licencia Creative Common Atribución-No Comercial 4.0 International (CC BY-NC 4.0) Revista de la Universidad Internacional del Ecuador. URL: https://www.uide.edu.ec/ 


\section{Desarrollo Social}

Se puede entender el Desarrollo Social (DS) como el bienestar de todos los individuos que conforman una sociedad y que tiene como intención primaria que éstos alcancen su máximo potencial y que se pueda lograr por medio de inversión privada la eliminación de barreras para que otras personas puedan alcanzar sus sueños con confianza y dignidad, desarrollándose de manera integral, sana e inclusiva. Los resultados obtenidos respecto al DS son los siguientes:

\section{Tabla 3}

Desarrollo social en relación a los derechos humanos en la región San Martín

\begin{tabular}{llll}
\hline Derechos humanos & & & \\
\hline Niveles & $\boldsymbol{n}$ & $\mathbf{\%}$ & \% acum. \\
\hline Existe mayor respeto a los derechos humanos & 0 & 0,00 & 0,00 \\
No existe un mayor respeto a los derechos humanos & 2 & 16,67 & 16,67 \\
No es un tema relevante a tratar & 10 & 83,33 & 100,00 \\
Total & 12 & 100.00 & \\
\hline
\end{tabular}

En la Tabla 3 puede observarse en relación a los "Derechos Humanos" que 16,67\% de los participantes considera que no existe un mayor respeto a los derechos humanos a diferencia de años pasados, y 83,33\% de los participantes no hizo referencia al asunto, por lo que se debe entender como no relevante en el contexto actual. Sin embargo, esta percepción difiere con el hecho mismo de que el terrorismo en la organización de Sendero Luminoso (SL) y el Movimiento Revolucionario Túpac Amaru (MRTA), ambos fraccionaron los Derechos Humanos en pro de los ideales que tenían (Cotler, 1997) y que, al ya no encontrarse presentes en la actualidad, el favorecimiento a tales derechos debe ser aún mayor, no obstante, en esta investigación se asume que para los participantes esto es casi imperceptible por el mismo hecho de que no implica en sí un conflicto en el presente.

\section{Tabla 4}

Desarrollo social en relación a la inclusión social en la región San Martín

\begin{tabular}{llll}
\hline Inclusión social & & & \\
\hline Niveles & $\boldsymbol{n}$ & \% & \% acum. \\
\hline Existe mayor inclusión social & 1 & 8,33 & 8,33 \\
No existe una mayor inclusión social & 2 & 16,67 & 25,00 \\
No es un tema relevante a tratar & 9 & 75,00 & 100,00 \\
Total & 12 & 100.00 & \\
\hline
\end{tabular}

En la Tabla 4 puede observarse en relación a la "Inclusión Social” en la región San Martín que para 8,33\% de los participantes existe una mayor inclusión social en la región San Martín, producto del esfuerzo de algunos gobernadores locales que hicieron posible la inclusión de personas especiales para obtener acceso a trabajo. Para el 16,67\% de los participantes no existe 
una mayor inclusión social en la región San Martín debido a que las autoridades muchas veces son corruptas y no hacen lo necesario para que los que menos tienen puedan conservar los suyo. Por último, el 75,00\% de los participantes no hizo referencia al asunto, por lo que no se debe considerar un asunto de vital importancia a diferencia de otras necesidades que es primordial atender en el contexto actual.

\section{Tabla 5}

Desarrollo social en relación al acceso a servicios en la región San Martín

\begin{tabular}{llll}
\hline Acceso a servicios & & & \\
\hline Niveles & $\boldsymbol{n}$ & \% & \% acum. \\
\hline Existe mayor acceso a servicios & 9 & 75,00 & 75,00 \\
No existe un mayor acceso a servicios & 3 & 25,00 & 100,00 \\
No es un tema relevante a tratar & 0 & 0,00 & \\
Total & 12 & 100.00 & \\
\hline
\end{tabular}

En la Tabla 5 puede observarse que, en relación al acceso a servicios en la Región San Martín, el 75,00\% de los participantes considera que existe mayor acceso a servicios principalmente en servicios de educación, agua, y salud, vivienda. El 25,00\% de los participantes considera que no existe un mayor acceso a los servicios pues pese a los avances aún es necesario mejoras respecto a la constancia del agua, el adecuado cableado de luz y una accesibilidad a alimentación.

\section{Tabla 6}

Desarrollo social en relación a la participación ciudadana en la región San Martín

\begin{tabular}{llll}
\hline Participación ciudadana & & & \\
\hline Niveles & $\boldsymbol{n}$ & \% & \% acum. \\
\hline Existe mayor participación ciudadana & 10 & 83,33 & 83,33 \\
No existe una mayor participación ciudadana & 1 & 8,33 & 91,67 \\
No es un tema relevante a tratar & 1 & 8,33 & 100,00 \\
Total & 12 & 100.00 & \\
\hline
\end{tabular}

En la Tabla 6 puede observarse que, en relación a la "Participación Ciudadana" el 83,33\% de los participantes considera que existe una mayor participación ciudadana en la región San Martín, ya que es parte de la idiosincrasia del sanmartinense, y se ve reflejado en múltiples situaciones: eventos de colaboración, convocatoria de autoridades (mesa ancha), y el emprendimiento propio de la gente en diferentes negocios de comercio. El 8,33\% de los participantes considera que no existe una mayor participación ciudadana en la región San Martín que se debe especialmente a migrantes que vienen a la región y que traen consigo su forma de pensar más indispuesto al trabajo al equipo (lo contrario que sucede con los que viven en esta región). Por último, el 8,3\% de los participantes no hizo referencia al asunto, por lo que no se debe considerar un asunto de vital importancia en el contexto actual. 


\section{Tabla 7}

Desarrollo social en relación a la migración en la región San Martín

\begin{tabular}{llll}
\hline Migración & & & \\
\hline Niveles & $\boldsymbol{n}$ & $\mathbf{\%}$ & \% acum. \\
\hline Existe mayor migración & 10 & 83,33 & 83,33 \\
No existe una mayor migración & 0 & 0,00 & 83,33 \\
No es un tema relevante a tratar & 2 & 16,67 & 100,00 \\
Total & 12 & 100.00 & \\
\hline
\end{tabular}

En la Tabla 7 puede observarse que, en relación a la migración en la región San Martín, que $83,33 \%$ de los participantes considera que existe una mayor migración en la región que se ha ocasionado principalmente por la llegada de la carretera marginal que ha provocado mayor conexión entre las ciudades, asimismo, la gran mayoría de personas que migra a la región es principalmente porque ven oportunidad de agricultura y comercio con mayores posibilidades que en otros lugares. El 16,67\% de los participantes no hizo referencia al asunto, que explica que no lo considera un asunto de vital importancia en el contexto actual.

\section{Tabla 8}

Desarrollo social en relación a la cultura en la región San Martín

\begin{tabular}{llll} 
Desarrollo cultural & & & \\
\hline Niveles & $\boldsymbol{n}$ & \% & \% acum. \\
\hline $\begin{array}{l}\text { Existe una diversificación en el desarrollo } \\
\text { cultural }\end{array}$ & 5 & 41,67 & 41,67 \\
$\quad \begin{array}{l}\text { No existe una diversificación en el desarrollo } \\
\text { cultural }\end{array}$ & 2 & 16,67 & 58,33 \\
$\quad \begin{array}{l}\text { No es un tema relevante a tratar } \\
\text { Total }\end{array}$ & 5 & 41,67 & 100,00 \\
\hline
\end{tabular}

En la Tabla 8 puede observarse en relación a la "Cultura" en la región San Martín que, $41,67 \%$ de los participantes considera que existe una diversificación en el desarrollo cultural la que muchas veces es llamada una "transculturización", lo que ha producido cambios en la misma cultura sanmartinense en relación a la comida y a las festividades (mezcladas). El 16,67\% de los participantes considera que no existe una diversificación en el desarrollo cultural debido a que existen zonas en donde todavía las comunidades se auto segmentan, o solo viven personas que migraron más no hay una mezcla en sí. El 41,67\% de los participantes no hizo referencia al asunto, que explica que no lo considera un asunto de vital importancia en el contexto actual. 


\section{Figura 2}

\section{Mapa conceptual del Desarrollo Social}

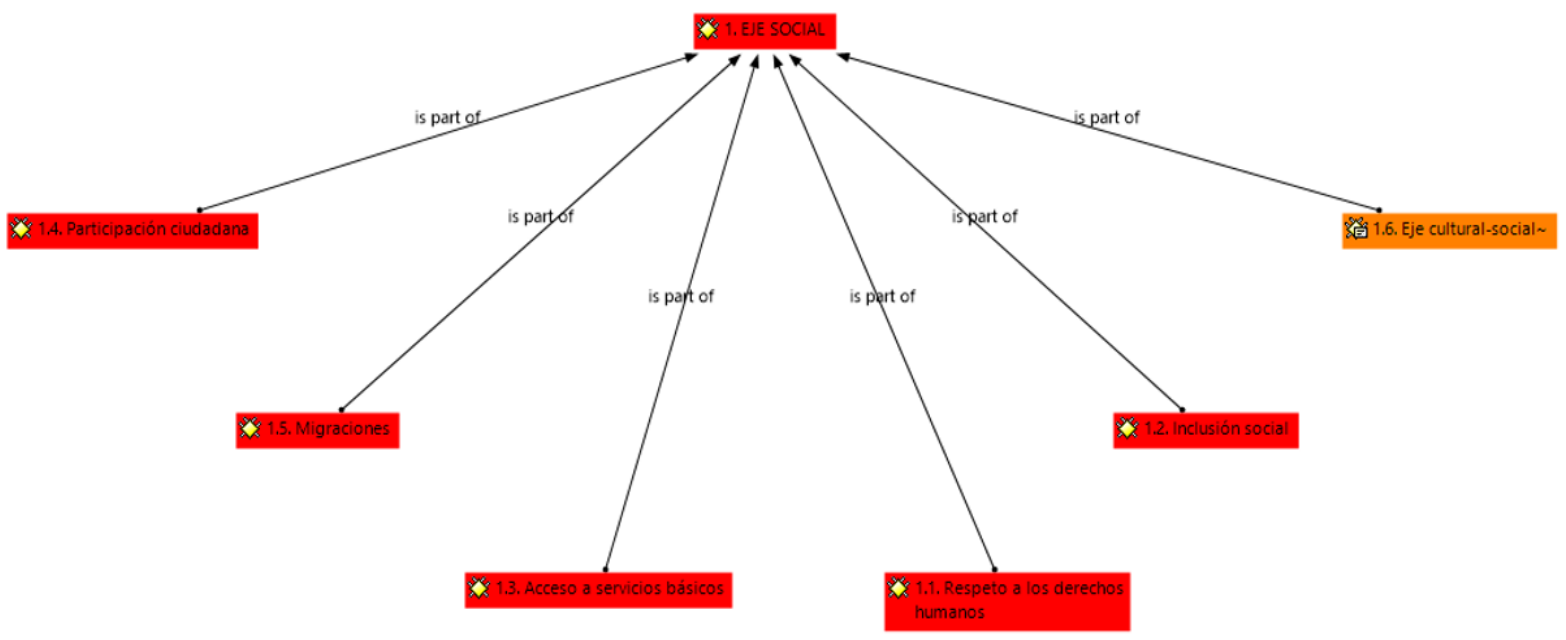

Tabla 9

Análisis de Co-Ocurrencia en relación al Desarrollo Social y los Factores que lo Impulsaron

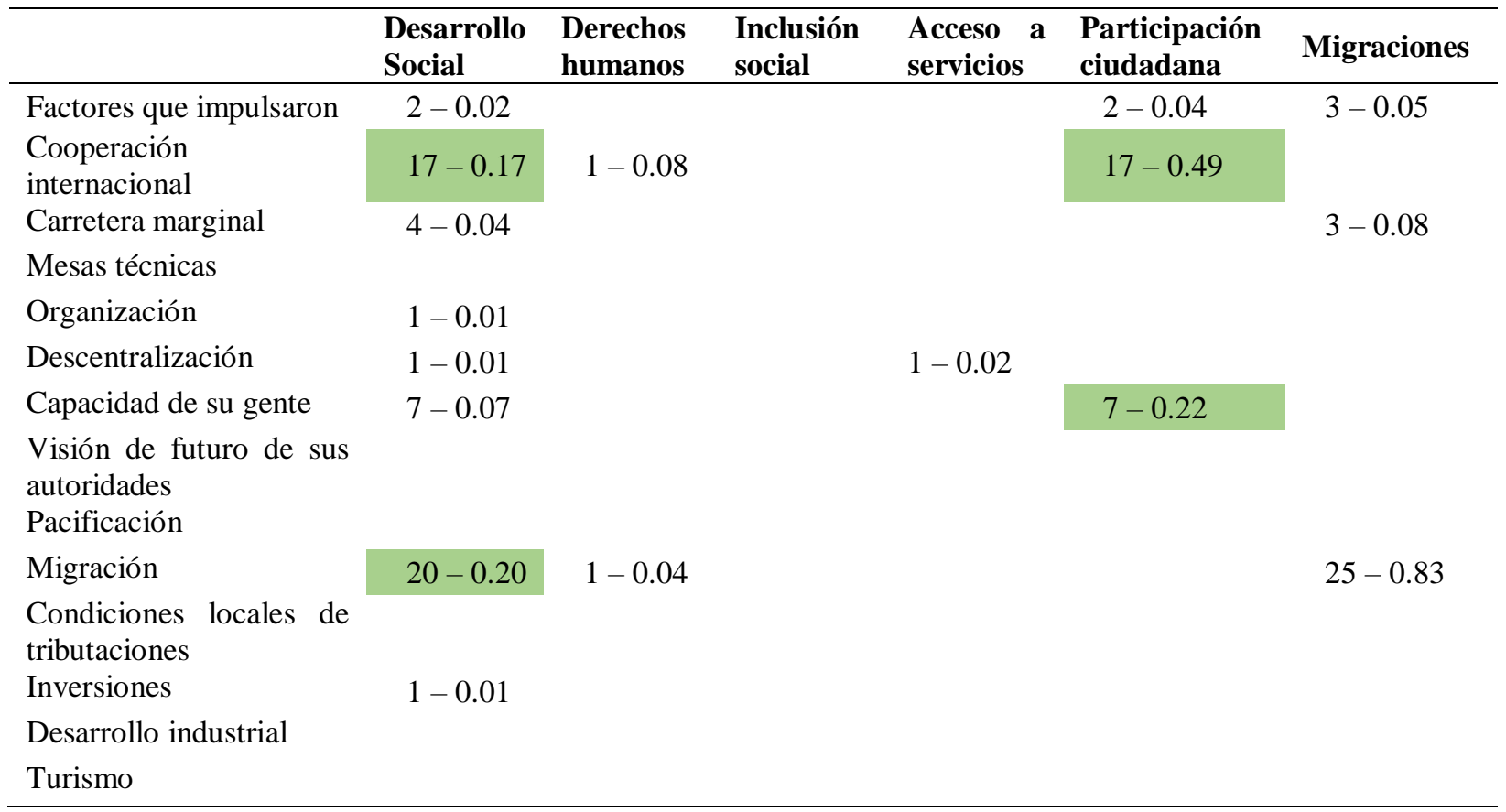

En la Tabla 9 se puede observar el coeficiente "C" de relación a los Factores que Impulsaron el Desarrollo Social, de los cuales se puede ver que la "Migración" ha sido el principal factor de Desarrollo Social de la región de San Martín $(C=0.20)$, seguido por la "Cooperación Internacional" $(\mathrm{C}=0.17)$ la misma que ha impulsado la "Participación Ciudadana" $(\mathrm{C}=0.49)$ y la "Capacidad de su Gente" ( $\mathrm{C}=0.22)$. Estos factores desde el enfoque cualitativo vendrían a ser los 
principales factores que impulsaron el Desarrollo Social en la región San Martín desde 1990 al 2000 .

\section{Desarrollo Económico}

Se puede entender el Desarrollo Económico (DE) como la creación de riqueza de la que se obtienen beneficios para la comunidad en la que intervienen diferentes instituciones locales para crear inversión que repercuta en hacer crecer su economía y mejorar la prosperidad y calidad de vida de todos los ciudadanos. Los resultados obtenidos respecto al DE son los siguientes:

\section{Tabla 10}

Desarrollo económico en relación a la diversidad económica en la región San Martín

\begin{tabular}{llll}
\hline Diversidad económica & & & \\
\hline Niveles & $\boldsymbol{n}$ & $\mathbf{\%}$ & \% acum. \\
\hline Existe mayor diversidad económica & 6 & 50,00 & 50,00 \\
No existe una mayor diversidad económica & 3 & 25,00 & 75,00 \\
No es un tema relevante a tratar & 3 & 25,00 & 100,00 \\
Total & 12 & 100.00 & \\
\hline
\end{tabular}

En la Tabla 10 puede observarse en relación a la "Diversidad Económica" en la región San Martín que, el 50\% de los participantes considera que existe una mayor diversidad económica en la región impulsada principalmente por el comercio que llegó como producto del incremento de las actividades turísticas, la descentralización y la migración. El 25,00\% de los participantes considera que no existe una mayor diversidad económica principalmente por que el turismo se concentra en las zonas más conocidas y no llega a las más lejanas, por otro lado, si bien San Martín es rico en producir cacao, café y arroz todavía no existen industrias en la región que puedan procesar la materia prima, en ese sentido la región es productora más no procesadora de su materia, lo que genera en la perspectiva de los participantes un gran retraso económico. El 25,00\% de los participantes no hizo referencia al asunto, lo que explica que no lo consideran un asunto de vital importancia en el contexto actual.

\section{Tabla 11}

Desarrollo económico en relación al cooperativismo en la región San Martín

\begin{tabular}{llll}
\hline Cooperativismo & & & \\
\hline Niveles & $\boldsymbol{n}$ & \% & \% acum. \\
\hline El cooperativismo ha sido vital para el desarrollo económico & 7 & 58,33 & 58,33 \\
El cooperativismo no ha sido vital para el desarrollo económico & 1 & 8,33 & 66,67 \\
No es un tema relevante a tratar & 4 & 33,33 & 100,00 \\
$\quad$ Total & 12 & 100.00 & \\
\hline
\end{tabular}

En la Tabla 11 puede observarse en relación al "Cooperativismo" en la región de San Martín que puede entenderse como las organizaciones de productores que existen actualmente en San Martín que impulsaron la economía de la región, el 58,33\% de los participantes considera que 
el cooperativismo ha sido vital para el desarrollo económico de la región, debido a que sin su compromiso, tiempo de dedicación e inversión, el desarrollo que actualmente experimenta San Martín no hubiera sido posible, se reconoce la labor de los programas de USAID, ESAN, DEVIDA, y las ONG's. El 8,33\% de los participantes considera que el cooperativismo no ha sido vital para el desarrollo económico de la región, la cual se puede considerar como una opinión aislada sin fundamento teórico válido. El 33,33\% de los participantes no hizo referencia al asunto, lo que explica que no lo consideran un asunto de vital importancia en el contexto actual.

\section{Tabla 12}

Desarrollo económico en relación a la actividad económica en la región San Martín

\begin{tabular}{llll}
\hline Actividad económica & & & \\
\hline Niveles & $\boldsymbol{n}$ & \% & \%cum. \\
\hline Existe mayor actividad económica & 9 & 75,00 & 75,00 \\
No existe una mayor actividad económica & 0 & 0,00 & 75,00 \\
No es un tema relevante a tratar & 3 & 25,00 & 100,00 \\
Total & 12 & 100.00 & \\
\hline
\end{tabular}

En la Tabla 12 puede observarse en relación a la "Actividad Económica" en la Región San Martín que, el 75,00\% de los participantes considera que existe una mayor actividad económica en la región, la que se ha logrado principalmente por la influencia del Turismo en diferentes puntos de la región y las inversiones en la región, incluyendo esfuerzos por sacar adelante industrias dedicadas al negocio de chocolate y del café, pero no a un nivel industrializado a gran escala como se espera que pueda ser. El 25,00\% de los participantes no hizo referencia al asunto, lo que explica que no lo consideran un asunto de vital importancia en el contexto actual.

\section{Tabla 13}

Desarrollo económico en relación a la infraestructura en la región San Martín

\begin{tabular}{llll}
\hline Infraestructura & & & \\
\hline Niveles & $\boldsymbol{n}$ & $\mathbf{\%}$ & $\mathbf{\% c u m}$. \\
\hline Existe mayor infraestructura & 9 & 75,00 & 75,00 \\
No existe una mayor infraestructura & 2 & 16,67 & 91,67 \\
No es un tema relevante a tratar & 1 & 8,33 & 100,00 \\
Total & 12 & 100.00 & \\
\hline
\end{tabular}

En la Tabla 13 puede observarse en relación a la "Infraestructura" en la región San Martín que, el 75,00\% de los participantes considera que existe una mayor infraestructura en la región producto de la migración que fue causada por la construcción de la carretera marginal que permitió una mejor conexión entre las ciudades, asimismo se resaltan construcciones dentro de la región como son colegios, hospitales, plaza y mejor infraestructura de la universidad. El 16,67\% de los participantes considera que no existe una mayor infraestructura en la región porque si bien hay aumento de obra las casas de las personas aún son muy pequeñas para la cantidad de familias que tienen, y por otro lado estas permanecen muchas veces en situaciones nada acogedoras. El 8,33\% de los participantes no hizo referencia al asunto, lo que explica que no lo consideran un asunto de vital importancia en el contexto actual. 


\section{Tabla 14}

Desarrollo económico en relación al presupuesto en la región San Martín

\begin{tabular}{llll}
\hline Presupuesto & & & \\
\hline Niveles & $\boldsymbol{n}$ & \% & \% acum. \\
\hline Existe mayor presupuesto & 8 & 66,67 & 66,67 \\
No existe un mayor presupuesto & 1 & 8,33 & 75,00 \\
No es un tema relevante a tratar & 3 & 25,00 & 100,00 \\
Total & 12 & 100.00 & \\
\hline
\end{tabular}

En la Tabla 14 puede observarse en relación al "Presupuesto" en la región San Martín que, el 66,67\% de los participantes considera que existe un mayor presupuesto en la región, debido a que alcaldes anteriores han hecho una buena gestión ejecutando obra, lo que ha generado un camino de mayor inversión por parte del estado para la región, asimismo muchas gestiones han hecho posible el alcance de dicho prepuesto para el beneficio social de las personas. El $8.33 \%$ de los participantes considera que no existe un mayor presupuesto en la región, por falta de una buena gestión, pues muchas de estos políticos se relacionan con actos corruptos. Por otro lado, un aspecto que hace que el presupuesto se detenga en la región es la falta de consecuencia en los proyectos causada por nuevas gestiones que no le dan el impulso que la anterior gestión tuvo. El 25,00\% de los participantes no hizo referencia al asunto, lo que explica que no lo consideran un asunto de vital importancia en el contexto actual.

\section{Figura 3}

Mapa conceptual del Desarrollo Económico

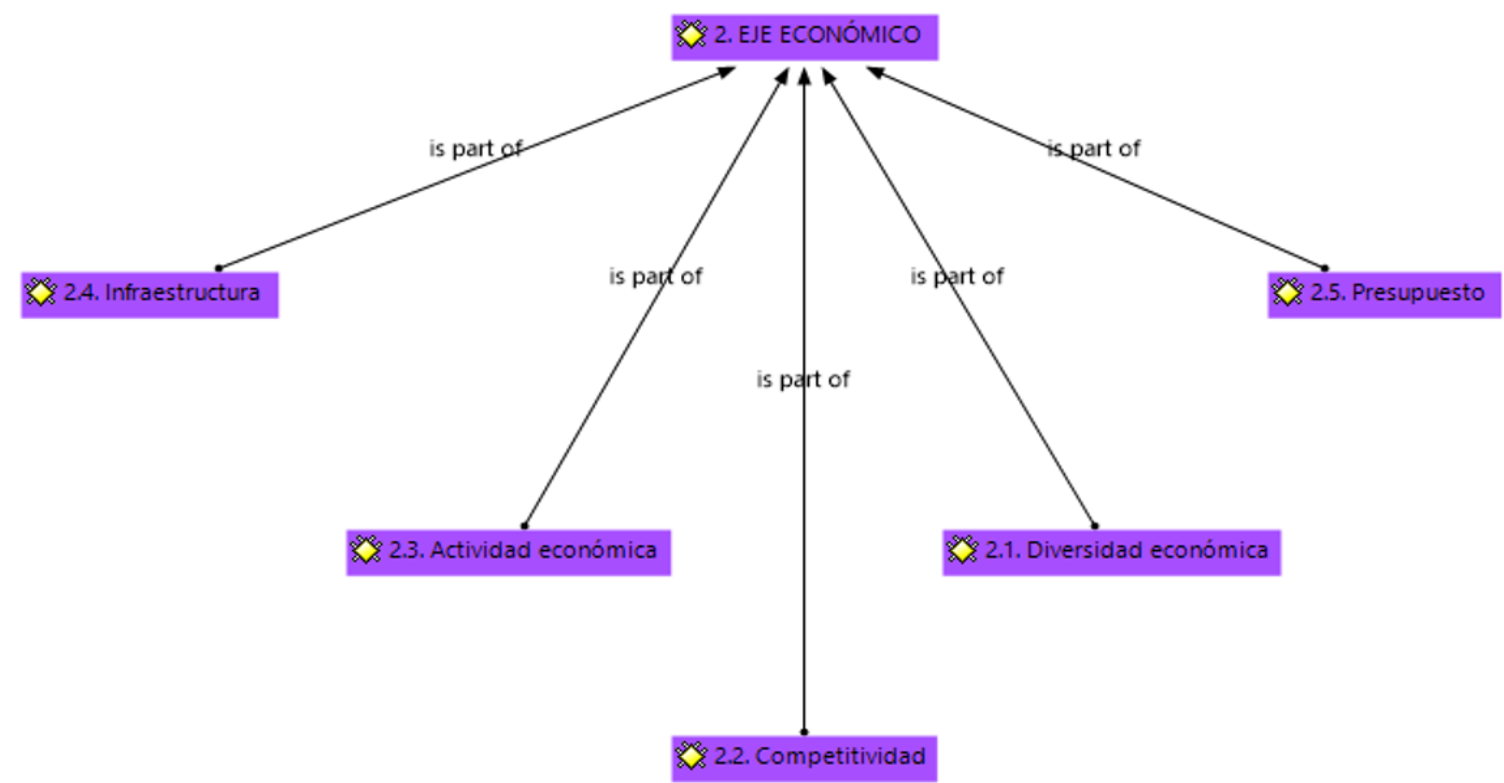




\section{Tabla 15}

Análisis de Co-Ocurrencia en relación al Desarrollo Económico y los Factores que lo Impulsaron

\begin{tabular}{|c|c|c|c|c|c|c|}
\hline & $\begin{array}{c}\text { Desarrollo } \\
\text { Económico }\end{array}$ & $\begin{array}{l}\text { Diversidad } \\
\text { económica }\end{array}$ & $\begin{array}{l}\text { Competiti } \\
\text { vidad }\end{array}$ & $\begin{array}{l}\text { Actividad } \\
\text { económica }\end{array}$ & Infraestructura & Presupuesto \\
\hline \multicolumn{7}{|l|}{ Factores que impulsaron } \\
\hline $\begin{array}{l}\text { Cooperación } \\
\text { internacional }\end{array}$ & $3-0.02$ & & & & $1-0.01$ & $1-0.02$ \\
\hline Carretera marginal & $2-0.02$ & & & & $2-0.03$ & \\
\hline \multicolumn{7}{|l|}{ Mesas técnicas } \\
\hline Organización & $1-0.01$ & & & & & \\
\hline Descentralización & $2-0.02$ & $2-0.06$ & & & & \\
\hline Capacidad de su gente & $2-0.02$ & & & & & $1-0.02$ \\
\hline \multicolumn{7}{|l|}{$\begin{array}{l}\text { Visión de futuro de sus } \\
\text { autoridades } \\
\text { Pacificación }\end{array}$} \\
\hline Migración & $3-0.02$ & $2-0.04$ & & & $2-0.03$ & \\
\hline \multicolumn{7}{|l|}{$\begin{array}{l}\text { Condiciones locales de } \\
\text { tributaciones }\end{array}$} \\
\hline Inversiones & $4-0.03$ & $1-0.03$ & $1-0.05$ & $2-0.05$ & & $1-0.03$ \\
\hline Desarrollo industrial & $6-0.05$ & $1-0.03$ & & $5-0.13$ & & \\
\hline Turismo & $15-0.12$ & $3-0.07$ & $3-0.09$ & $9-0.18$ & & \\
\hline
\end{tabular}

En la Tabla 15 se puede observar el coeficiente " $C$ " de relación a los Factores que Impulsaron el Desarrollo Económico, de los cuales se puede ver que el "Turismo" ha sido el principal factor de Desarrollo Económico de la Región de San Martín $(\mathrm{C}=0.12)$, seguido por el "Desarrollo Industrial" ( $\mathrm{C}=0.13)$ la misma que ha impulsada por la "Descentralización" $(\mathrm{C}=0.06)$ y las "Inversiones" $(\mathrm{C}=0.05)$. Estos factores desde el enfoque cualitativo vendrían a ser los principales factores que impulsaron el Desarrollo Económico en la Región San Martín desde 1990 al 2000.

\section{Desarrollo del Medioambiente}

Se puede entender el Desarrollo del Medioambiente como un desarrollo económico y social que respete el medio ambiente. El objetivo del desarrollo del medioambiente en principio es hacerlo sostenible, es decir que se hagan proyectos viables y conciliar los aspectos económicos, sociales y ambientales de las actividades humanas. Se trata de avanzar en estas áreas sin tener que destruir el medio ambiente. Los resultados obtenidos respecto al DMA son los siguientes:

\section{Tabla 16}

Desarrollo del medioambiente en relación a su cuidado del medioambiente en la región San Martín

\begin{tabular}{llll}
\hline Niveles & $\boldsymbol{n}$ & \% & \% \\
\hline Existe mayor cuidado del medioambiente & 4 & 33,33 & 33,33 \\
No existe un mayor cuidado del medioambiente & 7 & 58,33 & 91,67 \\
No es un tema relevante a tratar & 1 & 8,33 & 100,0 \\
Total & 12 & 100.00 & \\
\hline
\end{tabular}

Esta obra se comparte bajo la licencia Creative Common Atribución-No Comercial 4.0 International (CC BY-NC 4.0) Revista de la Universidad Internacional del Ecuador. URL: https://www.uide.edu.ec/ 
En la Tabla 16 puede observarse en relación al "Cuidado del Medioambiente” en la región San Martín que, 33,33\% de los participantes considera que existe un mayor cuidado del medioambiente, esta percepción principalmente se sustenta en las ciudades donde el impacto ambiental no es muy notorio, así también perciben que el saneamiento en San Martín ha descontaminado más los ríos en especial el del Huallaga y que se han elaborado documentos de protección al medioambiente o zonas ecológicas reservadas donde el gobierno regional cuida y mantiene de manera directa. El 58,33\% de los participantes considera que no existe un mayor cuidado del medioambiente debido a que la deforestación todavía continúa dentro de la ciudad a causa de las inmobiliarias quienes venden terreno donde pueden hacerlo, asimismo esta deforestación, aunque no es tan marcada como hubo en años anteriores donde la regulación era menor, todavía continúa por la expansión de las ciudades. El 8,33\% de los participantes no hizo referencia al asunto, lo que explica que no lo consideran un asunto de vital importancia en el contexto actual.

\section{Tabla 17}

Desarrollo del medioambiente en relación al uso adecuado de recursos naturales en la región San Martín

\begin{tabular}{llll}
\hline Uso adecuado de recursos naturales & & & \\
\hline Niveles & $\boldsymbol{n}$ & \% & \% acum. \\
\hline Existe un uso adecuado de recursos naturales & 6 & 50,00 & 50,00 \\
No existe un uso adecuado de recursos naturales & 3 & 25,00 & 75,00 \\
No es un tema relevante a tratar & 3 & 25,00 & 100,00 \\
Total & 12 & 100.00 & \\
\hline
\end{tabular}

En la Tabla 17 puede observarse en relación a "Uso adecuado de Recursos Naturales" en la región de San Martín que, el 50,00\% de los participantes percibe que existe un uso adecuado de los recursos naturales, esto principalmente porque algunas municipalidades y gobiernos regionales han asumido el cuidado de la flora y la fauna de la región, además porque San Martín fue la primera región que tuvo competencias en el tema forestal y porque su riqueza de flora y fauna permite que sea una de las regiones con capacidad de producir recursos con mayor diversidad. El 25,00\% de participantes considera que no existe un uso adecuado de recursos naturales principalmente porque aún no se logra controlar la deforestación en las zonas más alejadas de San Martín, donde la presencia del Estado no se hace presente. El $25,00 \%$ de los participantes no hizo referencia al asunto, lo que explica que no lo consideran un asunto de vital importancia en el contexto actual.

\section{Tabla 18}

Desarrollo del medioambiente en relación a la protección de riesgos y desastres en la región San Martín

\begin{tabular}{llll}
\hline Niveles & $\boldsymbol{n}$ & \% & \% acum. \\
\hline Existe una protección de riesgos y desastres & 1 & 8,33 & 8,33 \\
No existe una protección de riesgos y desastres & 0 & 0,00 & 8,33 \\
No es un tema relevante a tratar & 11 & 91,67 & 100,00 \\
Total & 12 & 100.00 & \\
\hline
\end{tabular}


En la Tabla 18 puede observarse en relación a la "Protección de Riesgos y Desastres" que, $8,33 \%$ de los participantes considera que existe una protección de riesgos y desastres en la región, pues antes existían desbordes de ríos, vientos huracanados y deslizamientos, sin embargo, a través de la municipalidad se buscaba la planificación para que haya inversión para contrarrestar esos fenómenos. El 91,67\% de los participantes no hizo referencia al asunto, lo que explica que no lo consideran un asunto de vital importancia en el contexto actual.

\section{Figura 4}

\section{Mapa conceptual del Desarrollo del Medioambiente}

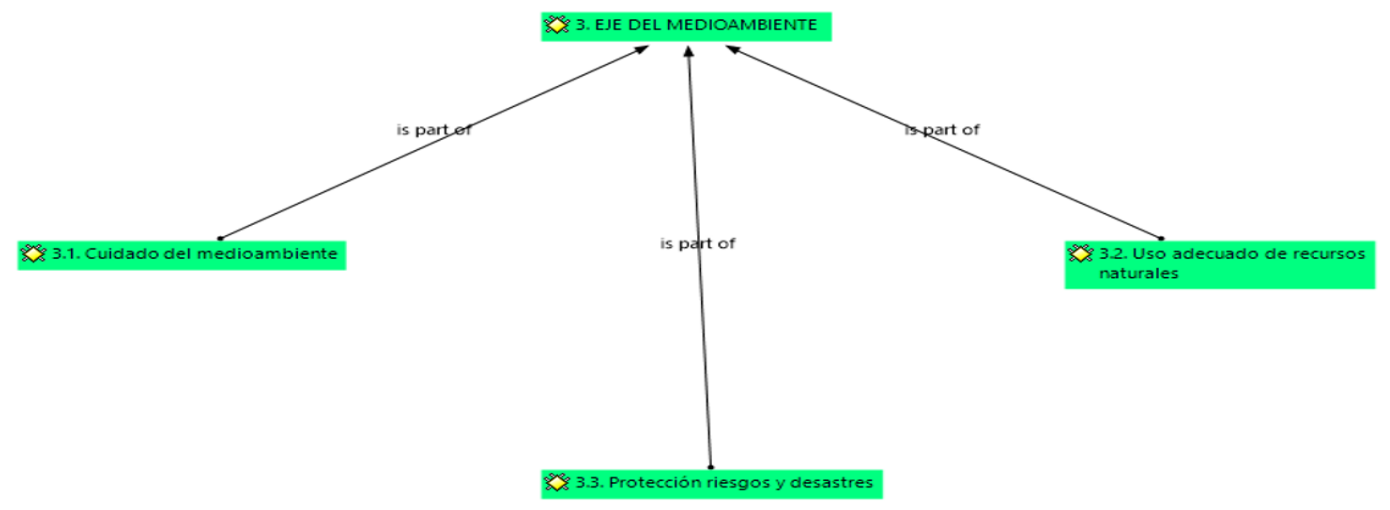

\section{Tabla 19}

Análisis de Co-Ocurrencia en relación al Desarrollo Medioambiental y los Factores que lo Impulsaron

\begin{tabular}{|c|c|c|c|c|}
\hline & $\begin{array}{l}\text { Desarrollo } \\
\text { Medioambiente }\end{array}$ & $\begin{array}{l}\text { Cuidado del } \\
\text { medioambiente }\end{array}$ & $\begin{array}{l}\text { Uso adecuado de } \\
\text { recursos }\end{array}$ & $\begin{array}{l}\text { Protección } \\
\text { de riesgos y } \\
\text { desastres }\end{array}$ \\
\hline \multicolumn{5}{|l|}{ Factores que impulsaron } \\
\hline Cooperación internacional & $1-0.01$ & $1-0.02$ & & \\
\hline Carretera marginal & $2-0.03$ & & $2-0.06$ & \\
\hline Mesas técnicas & $1-0.02$ & $1-0.03$ & & \\
\hline Organización & $1-0.02$ & & $1-0.03$ & \\
\hline \multicolumn{5}{|l|}{ Descentralización } \\
\hline \multicolumn{5}{|l|}{ Capacidad de su gente } \\
\hline \multicolumn{5}{|c|}{ Visión de futuro de sus autoridades } \\
\hline \multicolumn{5}{|l|}{ Pacificación } \\
\hline Migración & & $4-0.07$ & & \\
\hline \multicolumn{5}{|c|}{ Condiciones locales de tributaciones } \\
\hline \multicolumn{5}{|l|}{ Inversiones } \\
\hline \multicolumn{5}{|l|}{ Desarrollo industrial } \\
\hline Turismo & $3-0.04$ & & $1-0.02$ & \\
\hline
\end{tabular}


En la Tabla 19 se puede observar el coeficiente "C" de relación a los Factores que Impulsaron el Desarrollo Ambiental, de los cuales se puede ver que la "Migración" ha sido el principal factor que ha incidido en el Desarrollo Medioambiental de la región de San Martín $(\mathrm{C}=0.07)$, seguido por el "Turismo" $(\mathrm{C}=0.04)$ la misma que ha impulsada por la "Carretera Marginal" $(\mathrm{C}=0.03)$. Estos factores desde el enfoque cualitativo vendrían a ser los principales factores que incidieron el Desarrollo Medioambiental en la región San Martín desde 1990 al 2000.

\section{Tabla 20}

Análisis de Co-Ocurrencia en relación al Desarrollo Medioambiental y las Actividades Económicas a partir de Recursos Naturales

\begin{tabular}{lcccc}
\hline $\begin{array}{c}\text { Actividades } \\
\text { económicas }\end{array}$ & $\begin{array}{c}\text { Desarrollo } \\
\text { Medioambiente }\end{array}$ & $\begin{array}{c}\text { Cuidado } \\
\text { medioambiente }\end{array}$ & $\begin{array}{c}\text { Uso adecuado de } \\
\text { recursos }\end{array}$ & $\begin{array}{c}\text { Protección } \\
\text { riesgos y desastres }\end{array}$ \\
\hline Algodón & $1-0.02$ & & $1-0.04$ & \\
Arroz & $2-0.03$ & $1-0.02$ & & $1-0.07$ \\
Cacao & $8-0.11$ & $1-0.02$ & $7-0.17$ & \\
Café & $10-0.14$ & $1-0.02$ & $8-0.19$ & \\
Coco & $1-0.02$ & & $1-0.04$ & \\
Ganado Vacuno & $2-0.04$ & $1-0.03$ & $1-0.04$ & \\
Maíz & $1-0.02$ & & $1-0.04$ & \\
Palma & $1-0.02$ & & $1-0.04$ & \\
Palmito & $1-0.02$ & & $1-0.04$ & \\
Pescado & $1-0.02$ & & $1-0.04$ & \\
Tabaco & $2-0.04$ & & $2-0.08$ & \\
Coca & $2-0.03$ & $3-0.07$ & & \\
Deforestación & $23-0.40$ & $15-0.34$ & $6-0.14$ & \\
\hline
\end{tabular}

En la Tabla 20 se puede observar el coeficiente "C" de relación a las Actividades Económicas basadas en Recursos Naturales que Incidieron el Desarrollo Ambiental, de los cuales se puede ver que la "Deforestación" ha sido el principal factor que ha incidido en el Desarrollo Medioambiental de la Región de San Martín $(\mathrm{C}=0.40)$, también relacionado con el "Cuidado del Ambiente" $(\mathrm{C}=0.34)$. Asimismo, se observa que tanto el café $(\mathrm{C}=0.14)$ y el cacao $(\mathrm{C}=0.11)$ son los recursos naturales más preciados por los pobladores sanmartinenses. Estas actividades económicas basadas en recursos desde el enfoque cualitativo vendrían a ser las principales actividades que incidieron el Desarrollo Medioambiental en la región San Martín desde 1990 al 2000 .

\section{Desarrollo Político Institucional}

Se puede entender el Desarrollo Político Institucional (DPI) como el papel que cumplen las instituciones en el bienestar social, económico y ambiental de su entorno bajo su jurisdicción, cumpliendo un rol activo, participativo y de doble línea que busque desde diferentes perspectivas la mejora continua de la calidad de vida de las personas. Los resultados obtenidos respecto al DPI son los siguientes: 


\section{Tabla 21}

Desarrollo político institucional en relación a la corrupción en la región San Martín

\begin{tabular}{llll}
\hline Corrupción & & & \\
\hline Niveles & $\boldsymbol{n}$ & $\mathbf{\%}$ & \% acum. \\
\hline Existe mayor corrupción & 4 & 33,33 & 33,33 \\
No existe mayor corrupción & 0 & 0,00 & 33,33 \\
No es un tema relevante a tratar & 8 & 66,67 & 100,00 \\
Total & 12 & 100.00 & \\
\hline
\end{tabular}

En la Tabla 21 puede observarse en relación a la "Corrupción" en la región San Martín se puede observar que, 33,33\% de los participantes perciben que en la actualidad existe una mayor corrupción en la región, por la gestión de algún alcalde que se vio involucrado en conflictos éticos ya sea de mala administración de recursos o por peculado. El 66,67\% de los participantes no hizo referencia al asunto, lo que explica que no lo consideran un asunto de vital importancia en el contexto actual o por otro lado tratan de minimizar dichos actos a través de la negación.

\section{Tabla 22}

Desarrollo político institucional en relación al cooperativismo en la región San Martín

\begin{tabular}{llll}
\hline Cooperativismo & & & \\
\hline Niveles & $\boldsymbol{n}$ & $\mathbf{\%}$ & $\mathbf{\%}$ acum. \\
\hline El cooperativismo impulsó el desarrollo & 7 & 58,33 & 58,33 \\
El cooperativismo no impulsó el desarrollo & 0 & 0,00 & 58,33 \\
No es un tema relevante a tratar & 5 & 41,67 & 100,00 \\
Total & 12 & 100.00 & \\
\hline
\end{tabular}

En la Tabla 22 puede observarse en relación al "Cooperativismo" en la región San Martín que, el 58,33\% de los participantes considera que el cooperativismo impulsó el desarrollo de la región, siendo estas principalmente organizaciones de productores que decidieron impulsar la producción de un elemento en San Martín, especialmente el cacao, el café o maíz, y que lograron salir adelante con esfuerzo y ahora se mantienen como rentables dentro del mercado nacional e internacional. Por otro lado, algunas de estas cooperativas no lograron despegar tan alto y se mantienen en la región como pequeñas asociaciones con pocas conexiones. El 41,67\% de los participantes no hizo referencia al asunto, lo que explica que no lo consideran un asunto de vital importancia en el contexto actual.

\section{Tabla 23}

Desarrollo político institucional en relación a la gobernabilidad en la región San Martín

\begin{tabular}{llll}
\hline Gobernabilidad & & & \\
\hline Niveles & $\boldsymbol{n}$ & $\mathbf{\%}$ & \% acum. \\
\hline Si existe gobernabilidad & 2 & 16,67 & 16,67 \\
No existe gobernabilidad & 9 & 75,00 & 91,67 \\
No es un tema relevante a tratar & 1 & 8,33 & 100,00 \\
Total & 12 & 100.00 & \\
\hline
\end{tabular}


En la Tabla 23 puede observarse en relación a la "Gobernabilidad" en la región de San Martín que, el 16,67\% de los participantes considera que si existió gobernabilidad en la región especialmente en la gestión de César Villanueva quien ha resaltado entre los participantes como un alcalde que buscó presupuesto, impulsó el desarrollo e hizo innovación en la región sanmartinense. El 75,00\% de los participantes considera que no existe gobernabilidad en la actualidad en la región debido a que los últimos alcaldes no han hecho más que llegar al poder para usarlo en su propio beneficio, algunos de ellos excluyeron de toda participación a la ciudadanía y a las ONG's, manifestando una gestión principalmente deficiente debido a que cada año el presupuesto para hacer obras en San Martín aumenta pero producto de la gestión éstos recursos muchas veces no se dejan sentir en la ciudadanía, lo que provoca un mayor malestar. El $8,33 \%$ de los participantes no hizo referencia al asunto, lo que explica que no lo consideran un asunto de vital importancia en el contexto actual.

\section{Tabla 24}

Desarrollo político institucional en relación a la municipalidad o gobierno regional en la región San Martín

\begin{tabular}{llll}
\hline Municipalidad o gobierno regional & & & \\
\hline Niveles & $\boldsymbol{n}$ & \% & \% acum. \\
\hline $\begin{array}{l}\text { La municipalidad o gobierno regional es importante en el } \\
\text { desarrollo }\end{array}$ & 2 & 16,67 & 16,67 \\
$\quad \begin{array}{l}\text { La municipalidad o gobierno regional no es importante en } \\
\text { el desarrollo }\end{array}$ & 9 & 75,00 & 91,67 \\
$\quad \begin{array}{l}\text { No es un tema relevante a tratar } \\
\text { Total }\end{array}$ & 1 & 8,33 & 100,00 \\
\hline
\end{tabular}

En la Tabla 24 puede observarse en relación a la "Municipalidad o Gobierno Regional" en la región de San Martín que, el 16,67\% de los participantes considera que la municipalidad o gobierno regional fue importante en el desarrollo de la región, debido a la gestión que hizo algún alcalde, logrando que San Martín se posicione como una de las regiones de mayor inversión en el Perú y que pueda ser considerado como un referente en tema de inversión y economía, inversión que continúa en bajos niveles para industrias locales, pero no para procesos revolucionarios que impacten la región. El 75,00\% de los participantes considera que la municipalidad o gobierno regional no es importante o trascendente para el desarrollo regional, por su mala gestión, su desconexión con el pueblo y sus principales necesidades, su falta de inclusión de participación ciudadana y la expectativa que se espera de un alcalde en la actualidad que es mucho más de la que se tenía en el pasado. El 8,33\% de los participantes no hizo referencia al asunto, lo que explica que no lo consideran un asunto de vital importancia en el contexto actual. 


\section{Figura 5}

Mapa conceptual del Desarrollo Político-Institucional

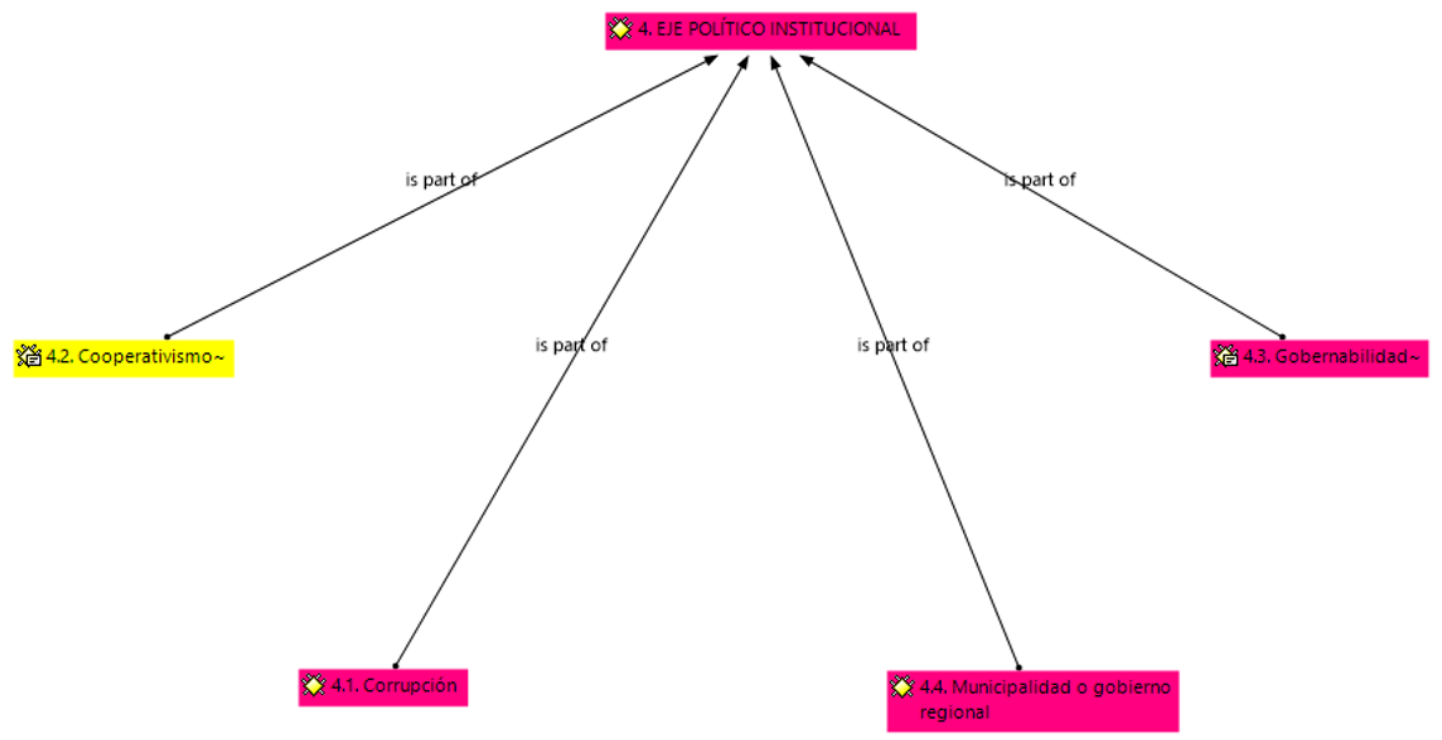

\section{Tabla 25}

Análisis de Co-Ocurrencia en relación al Desarrollo Político-Institucional y los Servicios Básicos

\begin{tabular}{lccccc}
\hline $\begin{array}{c}\text { Servicios } \\
\text { Básicos }\end{array}$ & $\begin{array}{c}\text { Desarrollo } \\
\text { Político- } \\
\text { Institucional }\end{array}$ & Corrupción & Cooperativismo & Gobernabilidad & $\begin{array}{l}\text { Municipalidad } \\
\text { o gobierno } \\
\text { regional }\end{array}$ \\
\hline Agua & $2-0.02$ & & & & $1-0.01$ \\
Desnutrición & $1-0.01$ & & & $1-0.03$ & $1-0.02$ \\
Educación & $2-0.02$ & $1-0.03$ & & & $1-0.01$ \\
Salud & $2-0.02$ & & & $1-0.01$ \\
Saneamiento & & & & $1-0.01$ \\
Servicios & $1-0.01$ & & & $1-0.02$ \\
Vivienda & & & & $1-0.02$ \\
\hline
\end{tabular}

En la Tabla 25 se puede observar el coeficiente "C" de relación a los Servicios Básicos impulsados por el Desarrollo Político-Institucional, donde ningún coeficiente de relación es significativo, por lo que se validan los resultados encontrados a partir de las entrevistas. Eso quiere decir que desde el enfoque cualitativo ningún Servicio Básico ha sido impulsado gracias al Desarrollo Político-Institucional en la región San Martín desde 1990 al 2000. 


\section{Tabla 26}

Análisis de Co-Ocurrencia en relación al Desarrollo Político-Institucional y los Factores que Impulsaron

\begin{tabular}{|c|c|c|c|c|c|}
\hline & $\begin{array}{l}\text { Desarrollo } \\
\text { Político- } \\
\text { Institucional }\end{array}$ & Corrupción & Cooperativismo & Gobernabilidad & $\begin{array}{l}\text { Municipalidad } \\
\text { o gobierno } \\
\text { regional }\end{array}$ \\
\hline $\begin{array}{l}\text { Factores } \\
\text { impulso }\end{array}$ & & & $5-0.09$ & $2-0.05$ & $2-0.02$ \\
\hline $\begin{array}{l}\text { Cooperación } \\
\text { internacional }\end{array}$ & $1-0.01$ & & $5-0.09$ & & $3-0.04$ \\
\hline $\begin{array}{l}\text { Mesas técnicas } \\
\text { Organización }\end{array}$ & & & & & $\begin{array}{l}1-0.02 \\
1-0.02\end{array}$ \\
\hline Descentralización & $3-0.04$ & & & $1-0.04$ & $2-0.03$ \\
\hline $\begin{array}{l}\text { Capacidad de su } \\
\text { gente }\end{array}$ & & & $1-0.02$ & & $1-0.01$ \\
\hline $\begin{array}{l}\text { Visión de futuro } \\
\text { de sus autoridades }\end{array}$ & & & & & $1-0.02$ \\
\hline Inversiones & $2-0.03$ & & $3-0.07$ & & $1-0.01$ \\
\hline
\end{tabular}

En la Tabla 26 se puede observar el coeficiente "C" en relación a los Factores de Desarrollo impulsados por el Desarrollo Político-Institucional, de los cuales se puede ver que el "Cooperativismo" ha sido el principal factor que impulsado por el Desarrollo Político-Institucional de la región de San Martín $(\mathrm{C}=0.09)$, lo que se asocia de igual manera con la "Cooperación Internacional" $(\mathrm{C}=0.09)$ y las "Inversiones" $(\mathrm{C}=0.07)$ que éstas han hecho en el Perú durante su ejecución. Eso quiere decir que desde el enfoque cualitativo tanto "Cooperativismo", "Cooperación Internacional" y las "Inversiones" ha sido lo que más ha impulsado el Desarrollo Político-Institucional en la Región San Martín desde 1990 al 2000.

\section{Tabla 27}

Análisis de Co-Ocurrencia en relación al Desarrollo Político-Institucional y las autoridades regionales o locales

\begin{tabular}{|c|c|c|c|c|c|}
\hline $\begin{array}{l}\text { Autoridades } \\
\text { regionales o } \\
\text { locales }\end{array}$ & $\begin{array}{l}\text { Desarrollo } \\
\text { Político- } \\
\text { Institucional }\end{array}$ & Corrupción & Cooperativismo & Gobernabilidad & $\begin{array}{l}\text { Municipalidad } \\
\text { o gobierno } \\
\text { regional }\end{array}$ \\
\hline $\begin{array}{c}\text { César } \\
\text { Villanueva }\end{array}$ & $6-0.07$ & & $1-0.02$ & $2-0.06$ & $2-0.03$ \\
\hline $\begin{array}{l}\text { Jaime } \\
\text { Bustamante }\end{array}$ & $1-0.01$ & & $1-0.03$ & & \\
\hline Pedro Bogarín & $3-0.04$ & & & & $1-0.02$ \\
\hline Víctor Noriega & $2-0.03$ & & $1-0.03$ & & \\
\hline
\end{tabular}

En la Tabla 27 se puede observar el coeficiente "C" en relación a las Autoridades Regionales que más han impactado el Desarrollo Político-Institucional, de los cuales se puede ver que el gobierno de "César Villanueva" ha sido el que más ha impulsado el Desarrollo PolíticoInstitucional de la Región de San Martín de manera positiva $(\mathrm{C}=0.09)$ haciendo que la “Gobernabilidad” sea más visible y cercana a la población $(\mathrm{C}=0.06)$. 


\section{Discusión}

El objetivo general de esta investigación es describir cuáles son los factores determinantes del desarrollo humano según la percepción de los agentes participantes en la región San Martín. Esta investigación encontró que el 41,67\% de los participantes considera que se alcanzó un nivel importante de desarrollo después de los 90's, el 41,67\% considera que se alcanzó un nivel medio de desarrollo después de los 90's, por último, el 16,67\% de los participantes no hizo referencia al asunto. Lo que podría resumirse en que un $83,34 \%$ de participantes considera que hubo un desarrollo de medio alto en la región luego de los 90 's.

El objetivo específico 1 de esa investigación es interpretar los factores determinantes del desarrollo social según la percepción de los agentes participantes en la región San Martín en 4 factores que conforman el eje social. Los resultados de esta investigación indican que el 16,67\% de los participantes consideran que no existe un mayor respeto a los "Derechos humanos" e "Inclusión social" en la actualidad. Asimismo, el 75,00\% de ellos considera que el servicio básico ha sido un avance significativo en el entorno social siendo esencialmente el acceso a "Educación", "Agua" y "Salud" lo que más se ha dejado sentir. Además, el 83,33\% de los participantes considera que existe una mayor participación ciudadana que fue impulsada por las cooperativas e inversiones del estado, y dos elemento que se obtiene a partir de la serendipia para esta sección fue que se incluyó además el Boom "Migratorio" que en la perspectiva del 83,33\% de los participantes, en los últimos años ha existido mayor migración de las personas para la región San Martín, lo que ha provocado cambios a nivel "Socio-Cultural" de los que 41,67\% de los participantes considera que ha existido una mayor diversificación de la cultura sanmartinense.

El objetivo específico 2 de esta investigación es analizar los factores determinantes del desarrollo económico según la percepción de los agentes participantes en la región San Martín, en 5 factores que conforman el eje económico. Los resultados de esta investigación indican que $50,00 \%$ de los participantes considera que en la actualidad existe una mayor "Diversidad Económica" que se alcanzó como un producto del "Cooperativismo" (58,33\%) que ha existido en la región, y la amplia variedad de "Actividad Económica" (75,00\%) que se alcanzó como producto de la "Infraestructura" que ha existido en la región. Esto ha hecho que San Martín se encuentre en una posición económica importante, que ha recibido en los últimos años una mayor cantidad de "Presupuesto" (66,67\%) por parte del Estado que no se deja ver en el entorno sanmartinense como un proyecto de vanguardia.

El objetivo específico 3 de esta investigación es comprender los factores determinantes del desarrollo del medio ambiente según la percepción de los agentes participantes en la región San Martín en 3 factores que conforman el eje medioambiental, donde la mayoría de los participantes considera que no existe un cuidado por el medioambiente $(58,3 \%)$, pero si una mayor cantidad de uso adecuado de recursos naturales $(50,00 \%)$ que ha ido en diversificación y explotación a medida que ha existido mayor inversión en las diferentes localidades y se ha dado el impulso para lograrlo. Por otro lado, en relación a la "Protección de riesgos y desastres" dado que las incidencias han sido pocas no se puede considerar como un aspecto trascendente del desarrollo medioambiental.

Un problema que persiste al largo de los años sin dudas ha sido la mayor deforestación en la región de San Martín en donde los agricultores, ganaderos, agroindustria y las concesiones 
forestales maderables han tenido un papel primario (Layza, Gonzales y Terán, 2018), tanto así que entre los años de 1973 al 2014 se ha dejado notar un cambio significativo en la temperatura, humedad y precipitación del entorno sanmartinense, conservándose aún el $60 \%$ de su territorio como bosques vírgenes con un total de 436,512 hectáreas de bosques, que dado el proceso de expansión también se estima se verán reducidos en un futuro (Calderón-Urquizo, 2020).

El objetivo específico 4 de esta investigación es interpretar los factores determinantes del desarrollo político institucional según la percepción de los agentes participantes en la Región San Martín en 3 factores que conforman el eje político-institucional, considerándose además como producto de la serendipia el "Cooperativismo" como parte importante de este eje. El 33,33\% de los participantes considera que en la actualidad existe mayor "Corrupción" lo que ha causado la percepción de "No gobernabilidad" entre sus habitantes $(75,00 \%)$, haciendo que la representación del Estado a través de la "Municipalidad o Gobierno Regional" sea casi nula (16,67\%). Por otro lado, un factor que realmente ha impulsado el Desarrollo Político-Institucional ha sido el "Cooperativismo" (58,33\%) considerándose el principal impulsor del Desarrollo Social y Económico debido a las inversiones que trajo al Perú.

\section{Conclusiones}

El objetivo general de esta investigación es descubrir cuáles son los factores determinantes del desarrollo humano, según la percepción de los agentes participantes en la región San Martín. Esta investigación encontró que los principales factores de Desarrollo Humano en la región San Martín fueron la "Migración", la "Cooperación Internacional", el "Turismo", y la "Capacidad de su gente". Según, el objetivo específico 1, interpretar los factores determinantes del Desarrollo Social, según la percepción de los agentes participantes en la región San Martín en 4 dimensiones que conforman el eje social, se encontró que los principales factores de Desarrollo Social en la región San Martín fueron la "Migración", la "Cooperación Internacional" que impulsó mucha participación ciudadana como producto de la "Capacidad de su gente".

Con respecto al objetivo específico 2, analizar los factores determinantes del Desarrollo Económico, según la percepción de los agentes participantes en la región San Martín, en 5 dimensiones que conforman el eje económico, se encontró que los principales factores de Desarrollo Económico en la región San Martín fueron el "Turismo", el "Desarrollo Industrial" que básicamente es artesanal, y la "Descentralización".

En relación al objetivo específico 3, comprender los factores determinantes del Desarrollo del Medio Ambiente, según la percepción de los agentes participantes en la región San Martín en 3 dimensiones que conforman el eje medioambiental, se encontró que los principales factores de Desarrollo Medioambiental en la región San Martín fueron la "Migración", el "Turismo" y la llegada de la "Carretera Marginal".

Finalmente, según el objetivo específico 4, interpretar los factores determinantes del Desarrollo Político Institucional, según la percepción de los agentes participantes en la región San Martín en 3 dimensiones que conforman el eje político-institucional, se halló que los principales factores de Desarrollo Político-Institucional la "Cooperación Internacional" y las "Inversiones" que trajo consigo. 


\section{Recomendaciones}

Fortalecer la infraestructura vial y de conexión con otras regiones del país que provean mejores oportunidades de Turismo en la región, diversificando las posibilidades de aumentar la diversificación económica a todas sus regiones. Fortalecer el diálogo entre las municipalidades y los gobiernos regionales y su conexión con la ciudadanía para conocer las necesidades y brindar un mejor acceso a servicios en su entorno. Ampliar la investigación desde el enfoque cuantitativo, diseñando instrumentos que permitan medir las categorías identificadas en los resultados de la investigación. Realizar investigaciones en otras regiones del país de tal manera que se contrasten los resultados para contribuir en la formación de patrones y ampliación de las teorías del desarrollo humano. Proponer el diseño y formulación de una política nacional en relación a la promoción del desarrollo humano regional.

\section{Referencias bibliográficas}

Ballón, M. (2015). San Martín: Un Viaje a la Otra Orilla. Hogar y Arquitectura: Revista Bimestral de La Obra Sindical Del Hogar, 12, 33-43.

Calderón-Urquizo, A. (2020). La degradación y deforestación del paisaje forestal en el departamento de San Martín, Perú. (Tesis inédita de maestría). Universidad de Barcelona. Barcelona - España.

CEPLAN. (2018). Perú: Informe Nacional 2018 para el desarrollo sostenible. Centro Nacional de Planeamiento Estratégico, Gobierno del Perú. https://www.ceplan.gob.pe/documentos_/peru-informe-nacional-2018-para-el-desarrollosostenible/

Checa-Olivas, M., De la Hoz-Rosales, B. y Cano-Guervos, R. (2021). The impact of employment quality and housing quality on human development in the European Union. In Sustainability (Switzerland), 13(2), 1-12. https://doi.org/10.3390/su13020969

Hernández-Sampieri, R., Fernández-Collado, C., y Baptista, L. (2010). Metodología de la Investigación.

Hurtado, A. (2019). Crecimiento económico, pobreza y desarrollo humano en el Perú. Revista Científica Pakamuros, 7(1), 68-79. https://doi.org/10.37787/pakamuros-unj.v7i1.77

Instituto Nacional de Estadística e Informática (2020). Población Peruana 2020. Estado de La Población Peruana 2020, 1-50. https://www.inei.gob.pe/media/MenuRecursivo/publicaciones_digitales/Est/Lib1743/Libro. pdf

Jimenez, V. y Comet, C. (2016). Case studies as a methodological approach. 3. ACADEMO Revista de Investigación en Ciencias Sociales y Humanidades. 3(2). https://revistacientifica.uamericana.edu.py/index.php/academo/article/view/54

Layza, R., Gonzales, F. y Terán, J. (2018). La deforestación y el cambio climático en la provincia de San Martín periodo: 1973 al 2014. Revista Ciencia y Tecnología, 14(2), 19-30.

Libanio, P. (2021). WASH services and human development: a tangible nexus for achieving waterrelated SDGs. Revista Internacional de Gestión de Cuencas Hidrográficas, 7500153132, 15715124. https://doi.org/10.1080/15715124.2021.1909603

Reglamento del Sistema Nacional de Ciencia y Tecnología e Innovación Tecnológica - SINACYT, 641 (2018). http://www.conacyt.mx 
Sen, A. (2000a). Desarrollo y libertad.

Sen, A. (2000b). El desarrollo como libertad. Gaceta Ecológica, 55, 14-20. https://www.redalyc.org/pdf/539/53905501.pdf

Tapia, A. (2020). La determinación del factor espacial en el desarrollo humano. (Tesis de bachiller). Pontifica Universidad Católica del Perú. http://hdl.handle.net/20.500.12404/17048

Zambrano, S., Cabanes, I., Salinas, J., Goyas, L. y Goyas, L. (2019). La igualdad de género y el desarrollo humano. Especial referencia a la República del Ecuador. Revista Metropolitana de Ciencias $\quad$ Aplicadas, 2(3), 120-128. https://remca.umet.edu.ec/index.php/REMCA/article/view/192 